\title{
PENGARUH PENGALAMAN PASIEN DAN CITRA PUSKESMAS TERHADAP KEPUASAN PASIEN DI PUSKESMAS BATUJAYA KARAWANG
}

\section{THE EFFECT OF PATIENT EXPERIENCE AND IMAGE OF PUSKESMAS ON PATIENT SATISFACTION IN PUSKESMAS BATUJAYA KARAWANG}

\author{
Chintia Nurdianty ${ }^{1}$, Ajat Sudrajat ${ }^{2}$ \\ Universitas Singaperbangsa Karawang ${ }^{1,2}$ \\ chintianurdianty123@gmail.com ${ }^{1}$
}

\begin{abstract}
Health is a basic need that is important to be able to live a decent and productive life in everyday life that everyone must have. This study aims to determine the effect of patient experience and image of the health center on patient satisfaction at Puskesmas Batujaya Karawang. The reason this research was conducted was because many people thought that the services and facilities at the puskesmas were poor. The research method used is descriptive verification. The sample of this study was 335 patients at Batujaya Health Center, using incidental sampling. The analytical method used is path analysis and hypothesis testing using the $t$ test and $F$ test and the coefficient of determination. From the test results, all hypotheses can be accepted. The coefficient value of determining patient experience and public health center image on patient satisfaction was obtained by $R$ Squer of 0.544 , meaning that $54.4 \%$ of patient satisfaction was influenced by these two variables, while 0.456 or $45.6 \%$ of patient satisfaction was influenced by other variables not examined in this study.
\end{abstract}

Keywords: Patient Experience, Health Center Image, Patient Satisfaction.

\begin{abstract}
ABSTRAK
Kesehatan adalah suatu kebutuhan dasar yang penting untuk dapat hidup layak dan produktif dalam kehidupan sehari-hari yang harus dimiliki oleh setiap orang. Penelitian ini bertujuan untuk mengetahui pengaruh pengalaman pasien dan citra puskesmas terhadap kepuasan pasien di Puskesmas Batujaya Karawang. Alasan penelitian ini dilakukan karena banyak masyarakat yang menganggap bahwa pelayanan dan fasilitas di puskesmas kurang baik. Metode penelitian yang digunakan adalah deskriftif verifikatif. Sampel penelitian ini sebanyak 335 pasien puskesmas Batujaya, dengan menggunakan Sampling insidental. Metode analisis yang digunakan adalah analisis jalur (Path Analysis) dan uji hipotesis menggunakan uji t dan uji $\mathrm{F}$ dan koefesien determinasi. Dari hasil pengujian seluruh hipotesis dapat diterima. Nilai koefesien determinasi pengalaman pasien dan citra puskesmas terhadap kepuasan pasien diperoleh $\mathrm{R}$ Squer sebesar 0,544 artinya 54,4\% kepuasan pasien dipengaruhui oleh kedua variabel tersebut, sedangkan 0,456 atau $45,6 \%$ kepuasan pasien dipengaruhi oleh variabel lain yang tidak diteliti dalam penelitian ini.
\end{abstract}

Kata Kunci: Pengalaman Pasien, Citra Puskesmas, Kepuasan Pasien. 


\section{PENDAHULUAN}

Kesehatan adalah suatu kebutuhan dasar yang penting untuk dapat hidup layak dan produktif dalam kehidupan sehari-hari yang harus dimiliki oleh setiap orang. Hal ini menjadi dasar kewajiban pemerintah dalam memberikan layanan kesehatan kepada masyarakat. Untuk itu diperlukan penyelenggarakan pelayanan kesehatan yang sekiranya biayanya dapat dikendalikan serta memberikan kualitas yang baik dan maksimal yang dapat membantu masyarakat.

Setiap upaya yang dilakukan oleh individu atau secara bersama-sama dalam suatu organisasi kesehatan yaitu tidak lepas untuk memelihara dan meningkatkan kesehatan, mencegah dan menyembuhkan penyakit serta memulihkan kesehatan, seseorang, keluarga, kelompok maupun masyarakat. Berbagai sarana pelayanan kesehatan yang terdapat ditemui dikalangan masyarakat sangat beragam seperti puskesmas, posyandu, klinik, praktik dokter, hingga rumah sakit umum atau pelayanan-pelayanan terpadu untuk penyakit khusus seperti dokter spesialis, klinik khusus anak balita, klinik jantung, klinik mata, klinik kecantikan, dan lain sebagainya.

Ditegaskan dalam undangundang 1945 pasal $28 \mathrm{H}$ ayat (1) menyatakan bahwa "setiap orang hendak hidup sejahtera lahir dan batin, bertempat tinggal, dan mendapatkan lingkungan hidup yang baik dan sehat serta berhak memperoleh pelayanan kesehatan" dan dalam pasal 14 UndangUndang Nomor 36 Tahun 2009 tentang kesehatan Pemerintah bertanggung jawab untuk merencanakan, mengatur, menyelenggarakan membina, dan mengawasi penyelenggaraan upaya kesehatan yang merata dan terjangkau oleh masyarakat (Sanah, 2017). Pusat Kesehatan Masyarakat (Puskesmas) merupakan salah satu organisasi kesehatan fungsional yang merupakan pusat pemeliharaan kesehatan untuk masyarakat yang menjadi peran serta memberikan pelayanan kesehatan secara menyeluruh dan terpadu kepada masyarakat di wilayah kerjanya dalam bentuk aktivitas tertentu.

Puskesmas Batujaya seringkali ditandai dengan adanya peningkatan angka keluhan pasien melalui kotak saran dan pengalaman pasien yang sudah berobat di Puskesmas Batujaya yaitu pengalaman pasien seperti kurang baiknya pelayanan yang diberikan, fasilitas berobat yang kurang memadai, fasilitas toilet/wc yang kurang nyaman dan bersih, fasilitas obat yang kurang lengkap, fasilitas ruang pegawai medis kurang memadai dan waktu jam dokter yang tidak sesuai, pengawai puskesmas yang kurang ramah, pendaftaran yang sering mengantri lama dan sering kali pemeriksaan/diagnosa yang lama untuk mengantri serta dokter yang sering tidak ada di Puskesmas Batujaya. Kue et al., dalam Eziswita \& Sukma (2018) Pengalaman pelanggan yaitu strategi atau cara untuk mengolah pengalaman pelanggan saat menggunakan produk atau jasa yang ditawarkan. Pelanggan saat ini menginginkan sesuatu yang lebih dari sekedar sebuah produk dan jasa, melainkan pengalaman yang menyenangkan untuk kepuasan pelanggan yang maksimal sesuai yang diharapkan.

Majid dalam Dewi \& Asminah (2018), menyatakan bahwa citra perusahaan adalah image yang terbentuk di masyarakat (konsumen atau pelanggan) tentang baik dan buruknya perusahaan. pengalaman pasien dan citra puskesmas menjadi sasaran utama pada suatu pelayanan yang telah diberikan, ketika suatu puskesmas memberikan pelayanan dengan baik dan maksimal terhadap 
pasien, akan berdampak baik bagi pengalaman pasien yang sudah merasakan produk atau jasa pelayanannya dan berdampak baik pula terhadap citra puskesmas karena dari pengalaman tersebut pasien akan berpresepsi baik terhadap citra puskesmas yang berujung pada kepuasan pasien.

Puskesmas Batujaya haruslah berfokus pada pasien, ini terkait dengan upaya Puskesmas Batujaya dalam rangka kedekatan pada pasien dan stakeholder lainnya. Untuk meningkatkan kepuasan bagi pasien harus adanya pendekatan terhadap pasien. Menurut Sabarguna dalam Setiawan (2018) ada dua hal penting sebagai subkriteria, yaitu kedekatan pada pasien, merupakan upaya mendapatkan pelayanan pada pasien dan mengembangkan budaya pelayanan, dan mendengarkan keluhan pasien, merupakan upaya mengumpulkan informasi dalam rangka mengetahui kebutuhan pasien dan kepuasan pasien. Menurut Tjiptono (2019), mengatakan bahwa kepuasan pelanggan adalah penilaian terhadap kepuasan produk atau jasa dalam memberikan tingkat pemenuhan kebutuhan konsumsi yang menyenangkan (Suyono et al., 2020).

\section{METODE PENELITIAN}

Pada penelitian ini menggunakan pendekatan kuantitatif yang dimana berkaitan dengan kepuasan pasien di Puskesmas Batujaya Karawang. Jumlah pasien sebanyak 31.235 pada tahun 2019 dengan menggunakan rumus pengambilan sampel menggunakan rumus Issac dan Michael dengan tingkat kesalahan 5\%. Oleh karena itu peneliti mengambil rata-rata sampel dengan 335 responden. Jenis data yang dipakai dalam penelitian ini adalah data primer dan sekunder yang bersumber dari kuesioner, wawancara, observasi serta Kepustakaan dan pengumpulan data lapangan.

\section{Definisi Operasional Variabel}

Dalam penelitian ini terdapat 2 jenis variabel, yakni variabel independen $(\mathrm{X})$ dan varibael depensen (Y). Untuk memperjelas masing-masing variabel, maka definisi operasional sebagi berikut:

1. Pengalaman pasien $\left(X_{1}\right)$. Ada lima elemen-elemen experiential marketing sebagai berikut:

a. Kepribadian (Personality), keseluruhan karakteristik perusahaan yang dipahami publik sasaran seperti perusahaan yang dapat dipercaya, perusahaan yang mempunyai tanggung jawab sosial.

b. Reputasi (Reputation), hal yang telah dilakukan perusahaan dan diyakini publik sasaran berdasarkan pengalaman sendiri maupun pihak lain seperti kinerja keamanan transaksi sebuah bank.

c. Nilai (Value), Nilai-nilai yang dimiliki suatu perusahaan dengan kata lain budaya perusahaan seperti sikap manajemen yang peduli terhadap pelanggan, karyawan yang cepat tanggap terhadap permintaan maupun keluhan pelanggan.

d. Identitas perusahaan (Corporate Identity), komponen-komponen yang mempermudah pengenalan publik sasaran terhadap perusahaan seperti logo, warna dan slogan.

2. Citra Puskesmas (X2). Setiap perusahaan pasti mempunyai citra di mata publiknya, citra tersebut dapat dipersepsikan berbeda-beda oleh setiap orang tergantung pada persepsi yang dilihat mereka mengenai apa yang mereka rasakan 
terhadap citra perusahaan tersebut. Citra itu dapat berdampak positif dan negatif. Citra perusahaan meliputi empat elemen sebagai berikut:

a. Kepribadian (Personality), keseluruhan karakteristik perusahaan yang dipahami publik sasaran seperti perusahaan yang dapat dipercaya, perusahaan yang mempunyai tanggung jawab sosial.

b. Reputasi (Reputation), hal yang telah dilakukan perusahaan dan diyakini publik sasaran berdasarkan pengalaman sendiri maupun pihak lain seperti kinerja keamanan transaksi sebuah bank.

c. Nilai (Value), Nilai-nilai yang dimiliki suatu perusahaan dengan kata lain budaya perusahaan seperti sikap manajemen yang peduli terhadap pelanggan, karyawan yang cepat tanggap terhadap permintaan maupun keluhan pelanggan.

d. Identitas perusahaan (Corporate Identity), komponen-komponen yang mempermudah pengenalan publik sasaran terhadap perusahaan seperti logo, warna dan slogan.

3. Kepuasan Pasien. Kepuasan pelanggan adalah respon yang diekspresikan pelanggan/pasien setelah mendapatkan pelayanan atau kinerja yang telah di berikan dan dilakukan oleh pegawai dan tenaga medis Puskesmas Batujaya. Terdapat empat dimensi pengukuran kepuasan pelanggan di bidang jasa sebagai berikut:

a. Keberadaan (Avaibility) . yaitu tingkatan keberadan dimana pelanggan dapat dengan mudah menemukan pihak yang memberikan pelayanan.

b. Ketanggapan (Responsiveness) yaitu tingkatan untuk mana pemberi pelayanan beraaksi cepat terhadap permintaan pelanggan.

c. Kenyamanan (Convinience), yaitu tingkat dimana pemberi pelayanan menunjukan prilaku dan gaya profesional yang tepat selama bekerja dengan pelanggan.

d. Kesesuaian waktu (Timelines), yaitu tingkatan dimana perkerjaan dapat dilaksakan dalam jangka waktu yang sesuai dengan perjanjian.

\section{Metode Analisis}

Pengujian yang dilakukan dalam penelitian ini menggunakan beberapa tahap antara lain validitas dan reabilitas instrumen, path analysis, pengujian hipotesis dilakukan uji $t$ dan uji f serta moefesien determinasi.

\section{HASIL DAN PEMBAHASAN Uji Validitas dan Reabilitas}

Berdasrkan hasil pengujian hasil penyebaran kuesioner terhadap 335 responden diperoleh hasil bahwa seluruh item kuesioner memiliki $r$ hitung lebih besar dari 0,3 ( $\mathrm{r}$ tabel) sehingga seluruh kuesioner di nyatakan valid. Selanjurnya dari hasil perhitungan uji reabilitas diperoleh hasil perhitungan untuk masing-masing variabel yaitu pengalaman pasien 0,852 , citra perusahaan 0,875 , dan kepuasan pasien 0,859 dimana seluruhnya lebih besar dari 0,7 sehingga semua item dinyatakan reliabel.

\section{Analisis Jalur/Path Analysis}

Hasil pengolahan data dengan menggunakan software SPSS 24.0, maka diperoleh koefesien jalur untuk setiap variabel pengalaman pasien $\left(\mathrm{X}_{1}\right)$ dan citra puskesmas $\left(\mathrm{X}_{1}\right)$ terhadap kepuasan pasien $(\mathrm{Y})$. 
Tabel 1 Pengaruh pengalaman pasien $\left(\mathrm{X}_{1}\right)$ citra puskesmas $\left(\mathrm{X}_{2}\right)$ terhadap kepuasan pasien (Y)

\begin{tabular}{|c|c|c|c|c|c|}
\hline \multirow[t]{2}{*}{ Variabel } & \multirow[t]{2}{*}{ Koef } & \multirow[t]{2}{*}{$\begin{array}{l}\text { Pengaruh } \\
\text { Langsung }\end{array}$} & \multicolumn{2}{|c|}{$\begin{array}{c}\text { Pengaruh Tidak } \\
\text { Langsung }\end{array}$} & \multirow[t]{2}{*}{$\begin{array}{r}\text { Subtotal } \\
\text { Pengaruh }\end{array}$} \\
\hline & & & $\mathrm{X} 1$ & $\mathrm{X} 2$ & \\
\hline $\begin{array}{l}\text { Pengalama } \\
\text { n Pasien } \\
\left(\mathrm{X}_{1}\right) \\
\end{array}$ & 0,392 & 0,154 & \multicolumn{2}{|r|}{0,116} & 0,270 \\
\hline $\begin{array}{l}\text { Citra } \\
\text { Puskesmas } \\
\left(\mathrm{X}_{2}\right) \\
\end{array}$ & 0,397 & 0,158 & 0,116 & -- & 0,274 \\
\hline \multicolumn{3}{|c|}{ Total Pengaruh } & & & 0,544 \\
\hline \multicolumn{5}{|c|}{ Pengaruh Variabel Lain $£$ Epsilon } & 0,456 \\
\hline
\end{tabular}

Sumber: Hasil Pengolahan Data, 2020

Berdasarkan Tabel 1 di atas menunjukkan bahwa total pengaruh yang disebabkan pengalaman pasien $\left(\mathrm{X}_{1}\right)$ citra puskesmas $\left(\mathrm{X}_{2}\right)$ terhadap kepuasan pasien (Y) yaitu sebesar 0 , 544. Adapun pengaruh variabel lain di luar model adalah sebesar $1-0,544=$ 0,456. Berdasarkan tabel diatas dapat diketahui pada kolom koefesien dapat ditetapkan bahwa persamaan jalurnya adalah sebagai berikut.

$Y=5,298+0,392 X_{1}+0,397 X_{2}+0,456 £$

Menunjukkan bahwa besaran derajat asosiatif atau koefesien jalur variabel citra puskesmas $\mathrm{X}_{2}(0,397)$ lebih tinggi dibandingkan dengan variabel pengalaman pasien $X_{1}(0,392)$, artinya citra puskesmas lebih berpengaruh terhadap kepuasan pasien (Y).

\section{Uji Hipotesis}

Korelasi pengalaman pasien $\left(\mathrm{X}_{1}\right)$ dengan citra puskesmas $\left(X_{2}\right)$

Pengujian hipotesis korelasi antara pengalaman pasien $\left(\mathrm{X}_{1}\right)$ dengan citra puskesmas $\left(\mathrm{X}_{2}\right)$ dilakukan dengan menggunakan hipotesis sebagai berikut:
Tabel 2 Uji Signifikansi Korelasi (uji-t)

\begin{tabular}{|c|c|c|c|}
\hline \multicolumn{4}{|c|}{ Coefficients ${ }^{a}$} \\
\hline & Standardized & & \\
\hline Model & Beta & $\mathrm{T}$ & Sig. \\
\hline $1 \quad$ (Constant) & & 9,086 &, 000 \\
\hline $\begin{array}{l}\text { Citra } \\
\text { Puskesmas }\end{array}$ & ,747 & 20,475 & 000 \\
\hline
\end{tabular}

a. Dependent Variable: Pengalaman Pasien Sumber: Hasil Pengolahan Data, 2020

Berdasarkan tabel diatas diperoleh $\mathrm{t}_{\text {hitung }} 20,475>$ peroleh $\mathrm{t}_{\text {tabel }}=$ $(1,967)$, maka dapat dinyatakan bahwa $\mathrm{H}_{0}$ ditolak maka $\mathrm{h}_{1}$ diterima, artinya korelasi antara pengalaman pasien $\left(\mathrm{X}_{1}\right)$ dengan citra puskesmas $\left(\mathrm{X}_{2}\right)$ perusahaan signifikan.

\section{Pengaruh Variabel secara Parsial (Uji t)}

Pengujian ini dilakukan dengan membandingkan nilai $\mathrm{t}$ hitung dengan $\mathrm{t}$ tabel dimana apabila nilai thitung $>$ ttabel atau sig $<0,05$ maka hipotesis diterima, sebaliknya jika $<$ ttabel atau sig $>0,05$ maka hipotesis ditolak. Dapat dilihat tabel pengujian uji $t$ (parsial) sebagai berikut:

Tabel 3 Uji Signifikansi Parsial (uji-t)

\begin{tabular}{|c|c|c|c|c|}
\hline \multicolumn{5}{|c|}{ Coefficients $^{\mathrm{a}}$} \\
\hline & \multicolumn{4}{|c|}{$\begin{array}{l}\text { Standardized } \\
\text { Coefficients }\end{array}$} \\
\hline & Model & Beta & $\mathrm{T}$ & Sig. \\
\hline \multirow[t]{3}{*}{1} & (Constant) & & 3,071 &, 002 \\
\hline & $\begin{array}{c}\text { Pengalaman } \\
\text { Pasien }\end{array}$ & ,392 & 7,042 & ,000 \\
\hline & $\begin{array}{c}\text { Citra } \\
\text { Puskesmas }\end{array}$ & ,397 & 7,125 & ,000 \\
\hline
\end{tabular}

a. Dependent Variable: Kepuasan Pasien Sumber: Hasil pengolahan data primer dengan SPSS 24, 2020

Berdasarkan tabel 3 di atas dapat disimpulkan bahwa nilai thitung variabel pengalaman pasien adalah 7,042 maka $t_{\text {hitung }}>t_{\text {tabel }}(7,042>1,967)$ dan nilai

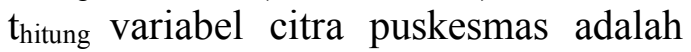
7,125 maka thitung $>t_{\text {tabel }}(7,125>1,967)$. Maka dapat dinyatakan bahwa $\mathrm{h}_{0}$ 
ditolak maka $\mathrm{h}_{1}$ diterima, variabel pengalaman pasien dengan kepuasan pasien dan citra puskesmas dengan kepuasan pasien berpengaruh positif dan signifikan $(0,000<0,050)$ secara parsial.

\section{Uji Signifikansi Simultan (Uji-F)}

Pengujian ini dilakukan dengan membandingkan nilai $\mathrm{f}$ hitung dengan $\mathrm{f}$ tabel dimana apabila nilai fhitung $>$ ftabel atau sig $<0,05$ maka hipotesis diterima, sebaliknya jika $<$ ftabel atau sig $>0,05$ maka hipotesis ditolak. Dapat dilihat tabel pengujian uji f (simultan) sebagai berikut:

Tabel 4 Uji Signifikansi Simultan (Uji-F)

\begin{tabular}{|c|c|c|c|}
\hline \multicolumn{4}{|c|}{ ANOVA $^{\mathbf{a}}$} \\
\hline & Model & $\mathrm{F}$ & Sig. \\
\hline 1 & Regression & 197,955 &, $000^{\mathrm{b}}$ \\
\hline \multicolumn{4}{|c|}{ Residual } \\
\hline \multicolumn{4}{|c|}{ Total } \\
\hline \multicolumn{4}{|c|}{ a. Dependent Variable: Kepuasan Pasien } \\
\hline \multirow{2}{*}{\multicolumn{4}{|c|}{$\begin{array}{l}\text { b. Predictors: (Constant), Citra Puskesmas, } \\
\text { Pengalaman Pasien }\end{array}$}} \\
\hline & & & \\
\hline \multicolumn{4}{|c|}{ Sumber: Hasil pengolahan data primer dengan } \\
\hline & 4,2020 & & \\
\hline
\end{tabular}

Berdasarkan tabel 4 terdapat nilai $\mathrm{F}$ hitung $>\mathrm{F}$ tabel $(197.955>$ 3.869) dan tingkat signifikansi $(0,000<0,050)$ dengan hipotesa $\mathrm{H}_{0}$ ditolak dan Ha diterima, sehingga dapat disimpulkan bahwa variabel bebas yaitu prngalaman pasien $\left(\mathrm{X}_{1}\right)$ dan citra puskesmas $\left(\mathrm{X}_{2}\right)$ secara bersama sama berpengaruh positif dan signifikan terhadap kepuasan pasien (Y) sebagai variabel terikat.

\section{Koefesian Determinasi}

Pengujian ini dilakukan untuk mengetahui varibel independen (X) terhadap variabel dependen (Y) dapat dilihat dalam tabel sebagai berikut:
Tabel 5 Uji Koefesien Determinasi

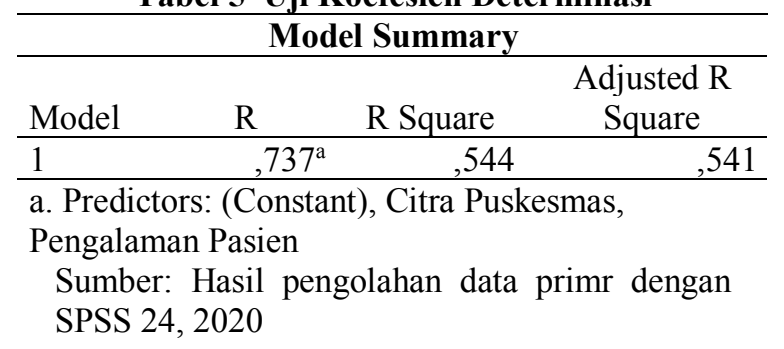

Berdasarkan tabel diatas diperoleh nilai koefesien korelasi (R) sebesar 0,737 yang berarti bahwa ada korelasi erat antara pengalaman pasien $\left(\mathrm{X}_{1}\right)$ citra puskesmas $\left(\mathrm{X}_{2}\right)$ terhadap kepuasan pasien (Y) yaitu sebesar $73,7 \%$. Besarnya pengaruh pengalaman pasien $\left(\mathrm{X}_{1}\right)$ citra puskesmas $\left(\mathrm{X}_{2}\right)$ terhadap variabel dependen kepuasan pasien (Y) ditunjukan oleh nilai $\mathrm{R}$ Square sebesar 0,544, artinya variabel Pengaruh pengalaman pasien $\left(\mathrm{X}_{1}\right)$ citra puskesmas $\left(\mathrm{X}_{2}\right)$ terhadap kepuasan pasien (Y) sebesar 54,4\% sisanya sebesar $45,6 \%$ di pengaruhi oleh faktor - faktor lain yang tidak termasuk dalam penelitian ini.

\section{Korelasi Antara Pengalaman Pasien dan Citra Puskesmas}

Berdasarkan tingkat korelasi yang kuat searah karena nilainya positif yang interval koefesiennya menunjukkan suatu yang kuat dan searah. Hal ini diperkuat pada penelitian terdahulu yang dilakukan oleh Hadi \& Terra (2017) mengenai variabel Experiential Marketing dan variabel brand image bahwa terdapat korelasi antara Experiential Marketing dan brand image.

\section{Pengaruh Parsial Pengalaman Pasien terhadap kepuasan pasien}

Memilki nilai koefesien sebesar $27 \%$. Artinya pengalaman pasien $\left(X_{1}\right)$ memiliki pengaruh yang positif terhadap kepuasan (Y). Hasil tersebut diperkuat dengan hasil penelitian terdahulu yang dilakukan oleh Yasintha 
(2016) variabel experiental marketing terhadap variabel kepuasan penumpang kereta api bisnis sebesar 0,58

\section{Pengaruh Citra Puskesmas terhadap Kepuasan Pasien}

Memiliki nilai koefesien sebesar 27,4\%. Artinya citra $\left(\mathrm{X}_{2}\right)$ memiliki pengaruh yang positif terhadap kepuasan pasien (Y). Hasil tersebut diperkuat dengan penelitian terdahulu yang dilakukan oleh Ciko, et.al (2020) mengenai Citra Perusahaan terhadap Kepuasan Pasien sebesar 11,98\%.

\section{Pengaruh Simultan Antara Pengalaman Pasien dan Citra Puskesmas terhadap Kepuasan Pasien}

Total pengaruh pengalaman pasien dan citra puskesmas terhadap kepuasan pasien sebesar 54,4\%. Hal ini menunjukkan bahwa masih ada variabel lain yang mempengaruhi kepuasan pasien di Puskesmas Batujaya sebesar 45,6\%. Hasil tersebut diperkuat dengan penelitian terdahulu yang dilakukan oleh Dwiastuti (2019) variabel experiental marketing dan brand image secara simultan berpengaruh positif dan signifikan terhadap kepuasan pelanggan Indihome dengan tingkat signifikansi sebesar 0,000 dan tingkat signifikansi yang dapat $(<)$ cronbach alpha 0,05 .

\section{PENUTUP}

\section{Kesimpulan}

1. Dari Korelasi Antara Pengalaman Pasien dan Citra Puskesmas Berdasarkan hasil tingkat korelasi dinyatakan kuat searah karena nilainya positif.

2. Dari hasil pengujian membuktikan bahwa hipotesis pertama yang menyatakan pengalaman pasien berpengaruh secara parsial terhadap kepuasan pasien di Puskesmas Batujaya karawang diterima.
3. Dari hasil pengujian membuktikan bahwa hipotesis kedua yang menyatakan pengalaman pasien berpengaruh secara parsial terhadap kepuasan pasien di puskesmas Batujaya Karawang diterima.

4. Pengalaman pasien dan citra puskesmas berpengaruh secara simultan terhadap kepuasan pasien di puskesmas batujaya karawang. Adanya pengaruh dominan dari variabel tersebut menunjukkan bahwa pengalaman pasien yang diberikan oleh Puskesmas dirasakan oleh pasien diberikan secara positif dan citra puskesmas di Puskesmas Batujaya Karawang sudah baik dinilai oleh masyarakat yang menjadikan pasien di Puskesmas Batujaya measa puas.

\section{Saran}

Oleh karena itu banyaknya puskesmas yang ada disetiap kecamatan atau daerah di kabupaten karawang, hendaknya melakukan penelitian di tempat yang berbeda sehingga hasil penelitian dapat dijadikan perbandingan mengingat masing-masing puskesmas memiliki citra masing-masing oleh masyarakat. Untuk penelitian di tahun berikutnya dan mendatang yang mengambil objek yang sama supaya menambahkan referensi di setiap teoritis dan data empirit.

\section{DAFTAR PUSTAKA}

Ciko, R., R., Dadan A., F, \& Ajat. (2020). Pengaruh Citra Perusahaan dan Kepercayaan terhadap Kepuasan Pasien Pada Rumah Sakit Mitra Medika Narom Kabupaten Bekasi. Jurnal Ekonomi dan Bisnis 7(1):41-49.

Dewi, Y., M., \& Asminah, R. (2018). Pengaruh Citra Puskesmas Dan Kualitas Pelayanan terhadap 
Kepuasan Pasien Rawat Inap di Puskesmas Dongko Trenggalek. Jurnal Aplikasi Bisnis 4(1): 1-4.

Dwiastuti, A., L. (2019). Pengaruh Experiental Marketing dan Brand Image terhadap Kepuasan Pelanggan PT. Telkom Akses Medan. Skripsi Sarjana Jurusan Manajemen Pada Fakultas Ekonomi Dan Bisnis Universitas Medan Area

Eziswita. \& Tri S. (2018). Analisis Experiential Marketing dan Pengaruhnya terhadap Kepuasan Pasien (Studi Pada Klinik Sehat Gajah Mada di Kota Padang) Padang). Ekonomi 4(1): 18-29.

Hadi P, \& Terra M. (2017). Analisis Experiential Marketing terhadap Brand Image Serta Dampaknya Pada Tourist Satisfaction di Kota Bandung. Jurnal Manajemen dan Bisnis: Performa 1(2): 54-74.

Sanah, N. (2017). Pelaksanaan Fungsi Puskesmas (Pusat Kesehatan Masyarakat) dalam Meningkatkan Kualitas Pelayanan Kesehatan di Kecamatan Long Kali
Kabupaten Paser. eJournal Ilmu Pemerintahan 5(1): 305-14

Setiawan, W. (2018). Pengaruh Kualitas Pelayanan Dan Kepuasan Terhadap Kepercayaan Pasien Bpjs di Puskesmas Cikampek. Skripsi Sarjana Jurusan Manajemen pada Fakultas Ekonomi dan Bisnis Universitas Singaperbangsa.

Soelasih, Y. (2016). Pengaruh Experiential Marketing dan Citra Merek terhadap Kepuasan Penumpang Kereta Api Bisnis. MIX: Jurnal Ilmiah Manajemen, 6(3), 156093.

Suyono, S., Purwati, A. A., \& Cutan, M. (2020). Peran Kualitas Pelayanan, Total Quality Management dan Promosi Terhadap Kepuasan Pelanggan. INVEST: Jurnal Inovasi Bisnis dan Akuntansi, 1(1), 45-56.

Tjiptono, F. \& Anastasia, D (2019). Kepuasan Pelanggan - Konsep, Pengukuran, dan Strategi. Yogyakarta: ANDI (Anggota IKAPI). 